DOI: https://doi.org/10.15688/nav.jvolsu.2019.1.1

UDC 902(470.56)

Submitted: 13.02.2019

LBC 63.4(2)(235.55)

Accepted: 14.03 .2019

\title{
ARCHAEOLOGICAL STUDIES OF M.G. MOSHKOVA IN ORENBURG REGION IN THE 1950-1960s AND THEIR SIGNIFICANCE FOR THE VOLGA-URAL REGION ARCHAEOLOGY ${ }^{1}$
}

\author{
Andrey A. Evgen'ev \\ Orenburg State Pedagogical University, Orenburg, Russian Federation
}

\begin{abstract}
The article considers the activity on studying archaeological sites of the Bronze Age, the Early Iron Age and the era of the Middle Ages in the east of Orenburg region performed by M.G. Moshkova in the $1950^{\text {th }}-$ $1960^{\text {th }}$. The group of the Southern Ural archaeological expedition under the leadership of M.G. Moshkova investigated Novo-Kumakskiy and Alandskoe I-III burial grounds. Studying the monuments of the east area of Sauromatian culture allowed to specify borders of their distribution and to reveal manifestations of fire cult in the funeral ceremony. The article introduces the idea of formation of the South Ural early Sarmatian culture on the basis of Sauromatian culture with participation of tribes of the forest-steppe Trans-Ural region and the Aral region in this process. Also M.G. Moshkova revealed and investigated burial and settlement sites of Alakul culture that allowed to make adjustments in the periodization of Andronovo cultural and historical community. Studying the burials of medieval nomads in Novo-Kumakskiy burial ground led to specification of the periodization of South Ural history in the first half of the $2^{\text {nd }}$ millennium BC. Thus, works of M.G. Moshkova in the east of Orenburg region promoted the solution of key problems of the Southern Cis-Ural and Trans-Ural history in the $2^{\text {nd }}$ millennium BC - the $2^{\text {nd }}$ millennium AD.

Key words: M.G. Moshkova, the early Iron Age, Sauromatian culture, early Sarmatian culture, Alakul culture.

Citation. Evgen'ev A.A., 2019. Archaeological Studies of M.G. Moshkova in Orenburg Region in the 19501960s and Their Significance for the Volga-Ural Region Archaeology. The Lower Volga Archaeological Bulletin, vol. 18, no. 1, pp. 8-13. (in Russian). DOI: https://doi.org/10.15688/nav.jvolsu.2019.1.1
\end{abstract}

УДК 902(470.56)

ББК 63.4(2)(235.55)

Дата поступления статьи: 13.02.2019

Дата принятия статьи: 14.03.2019

\section{РАБОТЫ М.Г. МОШКОВОЙ В ОРЕНБУРГСКОЙ ОБЛАСТИ В 1950-1960-е ГОДЫ И ИХ ЗНАЧЕНИЕ ДЛЯ АРХЕОЛОГИИ ВОЛГО-УРАЛЬСКОГО РЕГИОНА ${ }^{1}$}

\section{Андрей Александрович Евгеньев}

Оренбургский государственный педагогический университет, г. Оренбург, Российская Федерация

Аннотация. В статье рассмотрена деятельность в 1950-1960-е гг. М.Г. Мошковой по изучению археологических памятников бронзового века, раннего железного века и эпохи средневековья на востоке Оренбургской области. Отрядом Южно-Уральской археологической экспедиции под руководством М.Г. Мошковой 
были исследованы могильники Ново-Кумакский и Аландское I-III. Изучение памятников восточного ареала савроматской культуры позволило уточнить границы ее распространения и выявить проявления культа огня в погребальном обряде. Была высказана мысль о складывании южноуральской раннесарматской культуры на основе савроматской при участии в этом процессе племен лесостепного Зауралья и Приаралья. Также М.Г. Мошковой были выявлены и исследованы погребальные и поселенческие памятники алакульской культуры, что позволило внести коррективы в периодизацию андроновской культурно-исторической общности. Изучение захоронений средневековых кочевников в Ново-Кумакском могильнике привело к уточнению периодизации истории Южного Урала в первой половине II тыс. до н.э. Таким образом, работы М.Г. Мошковой на востоке Оренбургской области способствовали решению ключевых проблем истории Южного Приуралья и Зауралья во II тыс. до н.э. - II тыс. н.э.

Ключевые слова: М.Г. Мошкова, ранний железный век, савроматская культура, раннесарматская культура, алакульская культура.

Цитирование. Евгеньев А. А., 2019. Работы М.Г. Мошковой в Оренбургской области в 1950-1960-е годы и их значение для археологии Волго-Уральского региона // Нижневолжский археологический вестник. Т. 18 , № 1. C. 8-13. DOI: https://doi.org/10.15688/nav.jvolsu.2019.1.1

В 1956-1974 гг. на территории Оренбургской области работала экспедиция, в разные годы существования носившая различные наименования - Чкаловская, Оренбургская, Южно-Уральская. Основными организаторами экспедиции являлись Институт археологии АН СССР, Оренбургский областной краеведческий музей и Государственный исторический музей. Главной задачей экспедиции было «изучение истории и культуры древних скотоводческо-земледельческих племен медного и бронзового веков (III-II тыс. до н.э.) и кочевников - сарматов, а также раскопки на основании государственного законодательства об охране исторических памятников, подвергающихся ограблению или распашке» [Смирнов, 19646, с. 17]. Наиболее значимые результаты деятельности экспедиции связаны прежде всего с раскопками могильников эпохи бронзы на западе и юге области, комплексов андроновского времени в Домбаровском районе (работы Еленовского отряда), погребальных памятников кочевников РЖВ в бассейнах рек Илек, Бузулук, Суундук и близ г. Орска. Общее руководство экспедицией осуществлял доктор исторических наук Константин Федорович Смирнов (1917-1980). Свое становление в качестве практикующего археолога прошла в составе Южно-Уральской экспедиции научный сотрудник Института археологии Марина Глебовна Мошкова.

М.Г. Мошкова участвовала в работе экспедиции в качестве научного сотрудника начиная с ее первого сезона и вплоть до середины 1960-х гг., была начальником раскопа на таких курганных могильниках эпохи бронзы и ранне- го железного века, как Близнецы, Тара-Бутак, Мечет-Сай, Герасимовка I, Шиханы. Уже с первых лет деятельности экспедиции М.Г. Мошкова начала самостоятельную полевую работу. В 1957 г. ей было поручено исследование производственного комплекса у с. Новая Белогорка, относящегося к эпохе средневековья, а с 1958 г. начинаются работы отряда под ее руководством в восточных районах Оренбургской области. В августе 1958 г. отрядом экспедиции под руководством М.Г. Мошковой был выполнен разведочный маршрут в окрестностях г. Орска и в бассейне р. Суундук, выявлено 28 пунктов нахождения памятников [Мошкова, 1961 , с. 115$]$, в том числе могильников, раскопки которых проводились М.Г. Мошковой в 1958, 1959, 1962, 1965 и 1966 гг. (см. таблицу) - НовоКумакский и Аландское I-III.

Раскопки в верхнем течении р. Суундук, у села Аландское по замыслу М.Г. Мошковой преследовали цель установления границ расселения сарматов и выяснения ответов на вопросы, связанные с культурными, торговыми и генетическими связями кочевников РЖВ, с проблемой соседства кочевого и оседлого хозяйственных укладов [Мошкова, 1972б, с. 51; 1961, с. 115-125]. У Аландского были раскопаны 11 курганов в составе трех курганных групп. Большинство погребений отнесено к савроматской культуре в ее самаро-уральском, по К.Ф. Смирнову, варианте. М.Г. Мошкова на основе анализа погребального обряда, набора бронзовых втульчатых наконечников стрел, акинаков, керамики, конского снаряжения, предметов туалета и культа датировала их VI-V вв. до н.э. 


\section{Основные результаты работ отряда М.Г. Мошковой на востоке Оренбургской области в 1950-1960-е годы}

\begin{tabular}{|c|c|c|c|}
\hline Год & Название подразделения & Исследованные комплексы & Датировка \\
\hline \multirow[t]{3}{*}{1958} & \multirow{3}{*}{$\begin{array}{l}\text { Оренбургский архео- } \\
\text { логический отряд } \\
\text { ИИМК и ООКМ }\end{array}$} & КМ Новый Кумак, кург. 1-3 & $\begin{array}{l}\text { Савроматская культура (кург. 2, 3); кочевники } \\
\text { XII-XIV вв. (кург. 1) }\end{array}$ \\
\hline & & КМ Аландское I, кург. 1 & Савроматская культура \\
\hline & & КМ Аландское II, кург. 1 & Савроматская и раннесарматская культура \\
\hline 1959 & $\begin{array}{l}\text { Оренбургский архео- } \\
\text { логический отряд ИА } \\
\text { АН СССР и ООКМ }\end{array}$ & КМ Новый Кумак, кург. 4-19 & $\begin{array}{l}\text { Алакульская культура (кург. 4); савроматская } \\
\text { культура (кург. 5-10; 15;17; 19); раннесармат- } \\
\text { ская культура (кург. 12;13;16;18); кочевники } \\
\text { XII-XIV вв. (кург. 11) }\end{array}$ \\
\hline 1962 & $\begin{array}{l}\text { Оренбургская археоло- } \\
\text { гическая экспедиция } \\
\text { ИА АН СССР и ООКМ }\end{array}$ & КМ Новый Кумак, кург. 14, 20-39 & $\begin{array}{l}\text { Алакульская культура (кург. 26, погр. 2; } \\
\text { кург. 27, погр. 1; кург. 30, погр. 1; кург. 31, } \\
\text { погр. 1; кург. 32, погр. 1); савроматская куль- } \\
\text { тура (кург. 14, погр. 1; кург. 26, погр. 1); ран- } \\
\text { несарматская культура (кург. 20; 21; 23; 24; 25; } \\
30, \text { погр. 2; 33, погр. 1;34); кочевники XII- } \\
\text { XIV вв. (кург. 28; 29; 35-39) }\end{array}$ \\
\hline \multirow{5}{*}{$\begin{array}{c}1965- \\
1966\end{array}$} & \multirow{5}{*}{$\begin{array}{l}\text { Оренбургский отряд } \\
\text { Южно-Уральской ар- } \\
\text { хеологической экспе- } \\
\text { диции ИА АН СССР и } \\
\text { ООКМ }\end{array}$} & КМ Аландское I, кург. 2 & \multirow[t]{3}{*}{ Савроматская культура } \\
\hline & & КМ Аландское II, кург. 2, 3 & \\
\hline & & КМ Аландское III, кург. 1-6 & \\
\hline & & КМ Кара-Бутак I & \multirow[t]{2}{*}{ Алакульская культура } \\
\hline & & Поселение Кара-Бутак I & \\
\hline
\end{tabular}

В кургане 1 I Аландской группы был отмечен довольно редкий погребальный обряд трупосожжение на горизонте. Место, где совершено трупосожжение, было огорожено каменными плитами, поставленными на ребро, которые, вероятно, выделяли место сожжения. Такая же каменная ограда была прослежена в кургане 2 этого же могильника и в кургане 2 могильника Аландское II. В кургане 6 III Аландской группы трупосожжение было совершено на деревянной конструкции, перекрывавшей могильные ямы. Наличие такой формы погребального обряда, как трупосожжение, свидетельствует, по М.Г. Мошковой, в пользу сильного почитания огня на северо-восточных окраинах савроматского мира и может говорить о роли в формировании савроматского населения носителей андроновских культур, а также о тесных связях местного населения с сакским миром [Мошкова, 19726, с. 75-78].

Особенностью курганов могильника Аландское III являлось наличие сложных надмогильных бревенчатых конструкций, перекрытых слоем кострища. Среди раскопанных в могильнике погребений особо выделяется диагональное захоронение женщины-жрицы под насыпью сдвоенного кургана 3-4 III Аландской группы. Над захоронением был сооружен бревенчатый настил, поверх которого был устроен ритуальный костер. Женский костяк лежал на настиле из березовых плашек под двойным слоем коры, строго по диагонали, головой на югозапад, сопровождался предметами жреческого культа - каменным жертвенником, бронзовым зеркалом, бусами, раковинами Grifea, фрагментами мела и реальгара. В малом западном кургане на уровне древнего горизонта лежали кости человека, барана, лошади и коровы, что указывает на совершение здесь жертвоприношения. По мнению М.Г. Мошковой, подобный погребальный обряд является «религиозно-социальным признаком, выделяющим погребенную из остальной массы населения» [Мошкова, 19726, с. 70-71].

Раскопки Ново-Кумакского курганного могильника, расположенного в 7 км к востоку от г. Орска, начались в 1958 г. работами Орского отряда ОАЭ во главе с М.Г. Мошковой. В 1958, 1959 и 1962 гг. было исследовано 39 курганов, погребения в которых относились, за редким исключением, к раннему железному веку. В дальнейшем, в 1971-1973 гг., раскопки Ново-Кумакского могильника были продолжены под руководством К.Ф. Смирнова [Смирнов, 1977]. Характерной чертой исследованных погребений являлось наличие сложных деревянных надмогильных сооружений и раннее (уже в V в. до н.э.) появление катакомб, дромосов и подбоев - признаков, отличающих погребения раннесарматской культуры [Мошкова, 1972a, с. 40-42]. 
Наиболее типичными для инвентаря раннесарматских погребений Ново-Кумакского могильника являются длинные мечи переходной формы, бронзовые втульчатые наконечники стрел, лепная круглодонная керамика яйцевидных и шаровидных форм, что позволило М.Г. Мошковой датировать эти погребения IV - началом III в. до н.э. [Мошкова, 1972а, c. 42-44]. Наличие в материалах могильника принципиально новых форм керамики является, по мнению М.Г. Мошковой, свидетельством влияния на культуру местных сарматов культуры соседних племен, предположительно, с территории лесостепного Зауралья и Казахстана [Мошкова, 1962, с. 227].

Главным итогом работ отряда М.Г. Мошковой на востоке Оренбургской области стало выявление особенностей восточного варианта савроматской и раннесарматской культур, уточнение восточных границ распространения кочевников РЖВ Южного Приуралья. Был исследован крупный памятник времени перехода от савроматской к прохоровской культуре Ново-Кумакский могильник. Изучение переходных форм инвентаря позволило выдвинуть предположение о сложении комплекса погребального ритуала раннесарматской культуры в приуральском варианте савроматской культуры при участии в этом процессе постороннего этнического элемента [Мошкова, 1972a, с. 4748]. Эти предположения Марина Глебовна последовательно развила в дальнейшем в своих работах, в частности, в монографии «Происхождение раннесарматской (прохоровской) культуры», в которой ее взгляды на данную проблему приобрели завершенный характер.

Основополагающей идеей работы М.Г. Мошковой является мысль о формировании археологического комплекса раннесарматской (прохоровской) культуры в среде савроматского населения Южного Приуралья. Также, по ее мнению, определенное значение в формировании раннесарматской культуры имели археологические культуры лесостепного Зауралья (главным образом гороховская) и, вероятно, Приаралья и Казахстана [Мошкова, 1974, c. 48].

Опираясь на материалы Ново-Кумакского могильника, М.Г. Мошкова аргументировала высказанную К.Ф. Смирновым гипотезу об относительной оседлости населения орен- бургских степей в раннем железном веке. В пользу этого говорит наличие в могильнике обширных могил с длинными дромосами, в которых были совершены коллективные последовательные захоронения, по существу, являвшихся семейными склепами. Таким образом, сарматы имели определенные маршруты кочевок и постоянные места стоянок, возвращаясь к своим могильникам неоднократно. Состав стада, отмеченный по материалам Аландских могильников (до $50 \%$ костей КРС), косвенно подтверждает это предположение [Мошкова, 1974, с. 49-50].

Помимо комплексов раннего железного века, отрядом М.Г. Мошковой на востоке Оренбуржья были открыты погребения и других эпох. Комплексы бронзового века НовоКумакского могильника содержали бронзовые изделия (нож, височные подвески, шилья, обломок желобчатого браслета) и керамику срубно-алакульского и кожумбердынского облика. Наличие в могильнике подобных форм керамики позволило Э.А. ФедоровойДавыдовой поставить вопрос о сосуществовании алакульских и федоровских памятников [Мошкова, Федорова-Давыдова, 1964, с. 141], что в дальнейшем было подтверждено работами на востоке Оренбургской области Еленовского отряда Е.Е. Кузьминой.

Также в Кваркенском районе в 19651966 гг. М.Г. Мошковой были произведены раскопки алакульских поселения и могильника у с. Кара-Бутак. К сожалению, результаты раскопок полностью не были опубликованы. В соответствии с исследовательскими ориентирами руководителей экспедиции в научный оборот был введен только подъемный материал раннего железного века, происходящий с верхних слоев Кара-Бутакского поселения и являющийся свидетельством наличия здесь кратковременной стоянки племен РЖВ - фрагмент керамики с тальком [Мошкова, 1974, с. 49] и обломок бронзовых стремевидных удил VIIVI вв. до н.э. [Смирнов, 1964а, с. 33]. Культурный слой Кара-Бутакского поселения, судя по характерным образцам керамики с уступом и зональным геометрическим орнаментом, относился к алакульской культуре. Этим же временем датируется могильник Кара-Бутак I, отличительной особенностью которого является большое количество детских погребений, в 
составе инвентаря - керамика с зональным орнаментом, пастовые бусы, фрагменты бронзовых украшений [Мошкова, 1965].

Также в процессе работ М.Г. Мошковой на Ново-Кумакском могильнике были изучены средневековые погребения, введенные в научный оборот В.А. Кригером [Кригер, 1983]. На основании анализа всей совокупности элементов погребального обряда и инвентаря ученый установил, что большинство погребений могильника относится к золотоордынскому языческому периоду (XIII - первая половина XIV в.).

Таким образом, работами отряда Оренбургской (Южно-Уральской) экспедиции ИА АН СССР под руководством М.Г. Мошковой в 1950-1960-е гг. были исследованы памятники, давшие основание для постановки и решения нескольких ключевых проблем южноуральской археологии:

- были изучены памятники восточного ареала савроматской культуры, что позволило в целом очертить границы ее распространения, а также выявить специфику погребального обряда, связанную с высоким уровнем проявления культа огня;

- были исследованы комплексы V-IV вв. до н.э., что позволило высказать мысль о формировании южноуральской раннесарматской культуры на основе савроматской при участии в этом процессе лесостепных племен Зауралья;

- были выявлены и исследованы погребальные и поселенческие памятники алакульской культуры эпохи поздней бронзы, что в совокупности с данными параллельно проводимых работ отрядов Э.А. Федоровой-Давыдовой и Е.Е. Кузьминой привело к пересмотру существовавшей к началу 1960-х гг. периодизации андроновской культурно-исторической общности;

- в Ново-Кумакском могильнике были изучены захоронения средневековых кочевников, что способствовало разрешению вопросов периодизации средневековой истории Южного Урала.

\section{ПРИМЕЧАНИЕ}

${ }^{1}$ Работа выполнена при поддержке Задания № 33.1389.2017/ПЧ на выполнение научно-исследовательской работы в рамках проектной части государственного задания в сфере научной деятельности Министерства образования и науки Российской
Федерации и при поддержке проекта РФФИ «Древности» № 18-09-40031.

The work was supported by Task no. 33.1389. $2017 / П Ч$ on performing research work within the project part of the state task in the field of scientific activity of the Ministry of Education and Science of the Russian Federation and by RFBR project “Antiquities" no. 18-09-40031.

\section{СПИСОК ЛИТЕРАТУРЫ}

Кригер В. А., 1983. Средневековые захоронения Ново-Кумакского могильника (Оренбургская область) // Советская археология. № 3. С. $171-187$.

Мошкова М. Г., 1961. Сарматские курганы в Оренбургской области // Краткие сообщения Института археологии. № 83. С. 115-125.

Мошкова М. Г., 1962. Ново-Кумакский курганный могильник близ г. Орска // Материалы и исследования по археологии СССР. № 115. М. : Изд-во АН СССР. С. 206-241.

Мошкова М. Г., 1965. Отчет о работе Южно-Уральской экспедиции в 1965 г. // Архив ИА РАН. Ф. Р-1. Д. 3976.

Мошкова М. Г., 1972а. Сарматские погребения НовоКумакского могильника близ г. Орска // Памятники Южного Приуралья и Западной Сибири сарматского времени. М. : Наука. С. 27-48.

Мошкова М. Г., 1972б. Савроматские памятники северо-восточного Оренбуржья // Памятники Южного Приуралья и Западной Сибири сарматского времени. М. : Наука. С. 49-78.

Мошкова М. Г., 1974. Происхождение раннесарматской (прохоровской) культуры. М. : Наука. 52 с.

Мошкова М. Г., Фёдорова-Давыдова Э. А., 1964. Погребения эпохи бронзы Ново-Кумакского могильника // Краткие сообщения Института археологии. № 101. С. 135-142.

Смирнов К. Ф., 1964а. Савроматы. Ранняя история и культура сарматов. М. : Наука. 379 с.

Смирнов К. Ф., 1964б. Состояние и задачи археологического исследования Оренбургской области // Археология и этнография Башкирии. Т. II. Уфа : БФ АН СССР. С. 16-23.

Смирнов К. Ф., 1977. Орские курганы ранних кочевников // Исследования по археологии Южного Урала. Уфа : БФ АН СССР. С. 3-51.

\section{REFERENCES}

Moshkova M.G. The report on work of the Southern Ural expedition in 1965. Arkhiv IA RAN, R-1, no. 3976. (in Russian). 
Kriger V.A., 1983. Mediaeval burials of the Novyi Kumak burial ground, Orenburg district. Sovetskaya arkheologiya, no. 3, pp. 171-187. (in Russian).

Moshkova M.G., 1961. Sarmatian barrows in the Orenburg region. Brief Communications of the Institute of Archaeology, no. 83, pp. 115-125. (in Russian).

Moshkova M.G., 1962. The Novo-Kumaksky burial ground near Orsk. Materialy i issledovaniya po arheologii SSSR, no. 115. Moscow, Academy of Sciences of the USSR, pp. 206-241. (in Russian).

Moshkova M.G., 1972a. Sarmatian burials of the NovoKumaksky burial ground near Orsk. Pamyatniki Yuzhnogo Priural'ya i Zapadnoy Sibiri sarmatskogo vremeni. Moscow, Nauka Publ., pp. 27-48. (in Russian).

Moshkova M.G., 19726. Sauromatian monuments of northeast Orenburg region. Pamyatniki Yuzhnogo Priural'ya $i$ Zapadnoy Sibiri sarmatskogo vremeni. Moscow, Nauka Publ., pp. 49-78. (in Russian).
Moshkova M.G., 1974. The origin of early Sarmatian (Prohorovka) culture. Moscow, Nauka Publ. 52 p. (in Russian).

Moshkova M.G., Fyodorova-Davydova E.A., 1964. The burials of Bronze Age of the Novo-Kumaksky burial ground. Brief Communications of the Institute of Archaeology, no. 101, pp. 135-142. (in Russian).

Smirnov K.F., 1964a. Sauromats. Early history and culture of Sarmatians. Moscow, Nauka Publ. 379 p. (in Russian).

Smirnov K.F., 19646. Status and objectives of the archaeological research of the Orenburg region. Arkheologiya i ehtnografiya Bashkirii, vol. II. Ufa, Bashkir branch of the AS USSR, pp. 16-23. (in Russian).

Smirnov K.F., 1977. The Orsk kurgans of early nomads. Issledovaniya po arkheologii Yuzhnogo Urala. Ufa, Bashkir branch of the AS USSR, pp. 3-51. (in Russian).

\section{Information about the Author}

Andrey A. Evgen'ev, Candidate of Sciences (History), Associate Professor, Department of Russian History, Orenburg State Pedagogical University, Sovetskaya St., 19, 460014 Orenburg, Russian Federation, oren-arch@mail.ru, https://orcid.org/0000-0002-6360-064X

\section{Информация об авторе}

Андрей Александрович Евгеньев, кандидат исторических наук, доцент кафедры истории России, Оренбургский государственный педагогический университет, ул. Советская, 19, 460014 г. Оренбург, Российская Федерация, oren-arch@mail.ru, https://orcid.org/0000-0002-6360-064X 